\title{
Camões em solo tropical: auto imagem do escritor e a autonomia literária no Brasil pós independência
}

Débora El-Jaick Andrade ${ }^{1}$

\section{Resumo}

A imagem do poeta lusitano renascentista, Luís de Camões (?-1524), foi reapropriada no período do Romantismo para simbolizar a nação independente, tanto quanto foi destacado seu sacrifício pelas letras e seu destino trágico. Conterrâneo do poeta renascentista, o escritor português Almeida Garrett (1799-1854) viveu em um momento conturbado da história portuguesa - a ocupação militar de 1807, o estabelecimento do rei no Rio de Janeiro e a revolução liberal do Porto. Garret escreveu no exílio na Inglaterra e depois na França, um poema consagrado a Camões, que inovou o panorama literário em 1825, em que enfatizava o sacrifício do poeta moderno por amor à arte e à literatura bem como a ingratidão dos contemporâneos, produzindo um “mito camoniano". Jovens literatos brasileiros, Domingos JoséGonçalves de Magalhães (1811-1882) e Manuel de Araújo Porto Alegre (1806-1879), ao procurar compor um repertório de obras para inaugurar uma literatura nacional, fizeramreferência ao "mito de Camões" pormeio de seus discursos, poemas e peças teatrais. Apesar da explícita rejeição à herança portuguesa em uma primeira fase após a independência, a alusão a Camões e a sua trágica morte tiveram, como sentido, fixar a auto-imagem dos literatos, de um lado, como aqueles que se destacavam por serem dotados de gênio e, de outro, identificá-los como incompreendidos pelasociedade.

\footnotetext{
${ }^{1}$ Professora adjunto 3 da área de teoria da História da Universidade Federal Fluminense (Campos dos Goytacazes-RJ). E-mail debandrade.andrade54@gmail.com
} 
Palavras-chave: Romantismo; Literatos-século XIX; Gênio nacional.

\section{Abstract}

The image of the portuguese renaissance poet, Luís de Camões, was reappropriated in brazilian soil during the romantic period to symbolize the independent nation, but he was equally distinguished for his sacrifice for his writing and his tragic destiny. The writer Almeida Garrett, Camões' fellow countryman, lived in troubled times in portuguese history - times of the military occupation of 1807, the establishment of the portuguese court and king in Rio de Janeiro, the liberal revolution in the city of Porto - and wrote in his exile in England and afterwards in France, where he composed a poem dedicated to Camões in 1825, which brought innovation to the literary panorama and emphatized the modern poet's sacrifice for arts and letters, as well as the ingratitude of his contemporaries, creating the myth of Camões. Domingos José Gonçalves de Magalhães and Manuel de Araújo Porto Alegre, as young brazilian men of letters, sought to compose a repertoire to found brazilian national literature. By doing so, they referred to the "mith of Camões" in their speeches, poems and play. In spite of the explicit rejection of the portuguese heritage in the first epoch after independence, the allusion to Camões and his tragic death had the purpose to fix the self image of the men of letters, as those who distinguish themselves for being provided with genius on one side, and as being misunderstood by society, on the other.

Keywords: Romanticism; Men of letters-XIXth centure; National genius. 


\section{Introdução}

A década de 1820 marcou os destinos políticos de brasileiros e portugueses, em meio a revoluções, emancipação política, lutas entre facções e guerra civil. Para os portugueses da metrópole, tinha-se a oportunidade de emergir da estagnação econômica, através do retorno do exclusivismo nas relações comerciais com sua colônia mais próspera. A independência do Brasil, sede do império ultramarino, revoga as expectativas dos lusitanos, deixando-os às voltas com embates entre liberalismo e absolutismo que envolveu a sucessão ao trono.

Com a emancipação, conquistada após lutas contra tropas fiéis às Cortes, é garantida a continuidade da monarquia bragantina e da escravidão, o que não significou a adesão ao projeto centralizador de um segmento dos proprietários provinciais, permanecendo o risco de dispersão nos anos subsequentes. A luta pela autonomia resultou na separação não apenas das metrópoles, mas das regiões coloniais entre si. Sendo assim, paralelamente à construção do Estado, foi fundamental a criação de uma "nova base para o edifício social [que] se achará no fortalecimento da idéia de nação, entendida como a comunidade dos homens que compartilham a mesma história e cultura". (FONTANA, 1998, p.117)

Conforme observou a historiadora Lúcia Bastos Neves, a emancipação constituiu tão somente um ponto de partida para a construção moderna de nação: "Logo, a partir do final de 1822, a palavra nação começava a despertar sentimento de separação, de distinção de um povo em relação ao outro, despontando a ideia de nacional, como oposto de estrangeiro"(NEVES,2011, p.97). O conceito de nação adquiria um significado cultural, enquanto uma "comunidade dotada de identidades singulares" (NEVES, 2011, p.97), que precisava ser incutido enquanto doutrina e difundido de modo a fazer frente à frágil unidade territorial, ameaçada pelos projetos separatistas que mediam forças com o projeto centralizador dos proprietários do centro sul, em particular 
durante o período regencial (1831-1840) e início do Segundo Reinado (1840-1889).

Em função destas lutas econômicas e simbólicas, acirram-se as rivalidades entre brasileiros e portugueses, assim como a lusofobia radicada entre a população, situadas em um momento de definição de identidades nacionais. Neste clima, a língua era elemento de identificação, tanto quanto a literatura seria afirmada em sua originalidade e particularidade, sobretudo, através de debates polêmicos na imprensa, pois a afirmação da autonomiae da vitalidade da literatura brasileiraenvolveu literatos da nova geração que se engajaram no desafio de produzir grandes monumentos da cultura nacional.

\section{Juventude literária e a produção de monumentos nacionais}

Alguns jovens estudantes brasileiros, nascidos no final do período colonial, estudantes em Paris - a capital cultural do mundo considerado "civilizado"- entre os anos 1830 e início dos anos de 1840, diagnosticaram que a nação que acabara de se tornar independente possuía uma cultura própria e florescente, atestada pela presença das artes, música, arquitetura, teatro e literatura.

Domingos José Gonçalves de Magalhães (1811-1882), Manuel de Araújo Porto Alegre (1806-1879) e João Manuel Pereira da Silva (18171898), escreveram e publicaram uma série de ensaios em dois números, a revista Niterói em Paris em 1836, que foi oferecida a seus pares, os demais sócios do Instituto Histórico de Paris. Considerada pela historiografia literária como primeira revista literária do Romantismo, a Niterói trazia vários ensaios que demonstravam a preocupação em traçar os esboços da história das artes e literatura no país, desde o período colonial.

Por exemplo, em seu "Ensaio sobre a História da literatura do Brasil", Gonçalves de Magalhães, queixava-se de que após "longo e 
enfadonho estudo" fracassou em esclarecer as datas de nascimento dos "nossos primeiros poetas", "que tanto apreço damos nós aos grandes homens, que nos honram, desses homens cuja herança é hoje nossa única glória”. (MAGALHÃES,1836, p.137). Reside neste ensaio um esforço de fixação de representantes das letras nascidos ou residentes no país e suas datas de nascimento, para "melhor conservar os monumentos dessa glória para as raças futuras a fim de que não nos exprobem nosso desmazelo, e de bárbaros não nos acusem". ${ }^{2}$ (MAGALHÃES,1836, p.137).

A imagem da jovem nação dependia de como o passado favorecesse, antecipasse e clareasse o futuro, e de como demonstrasse a pré-existência de elementos de civilização no Brasil. Logo, no sentido referido por Magalhães, "conservar os monumentos" significaria tanto descobrir testemunhos valiosos de acontecimentos passados, preferencialmente escritos, recuperando os feitos e a biografia de "gênios" e restituir a glória à sociedade de onde eram originários, quanto produzir novos testemunhos destaglória no presente. Gonçalves de Magalhães consideravaimportante garantir a publicação de um "monumento verdadeiramente nacional e poético" "que fosse um documento necessariamente original da cultura brasileira, que equiparasse o Brasil às demais civilizações da época. (ANDRADE, 2008).

${ }^{2}$ Outras obras consideradas fundadoras da história da literatura são as de Ferdinand Denis, Resumé de l'histoire Litteraire Du Portugal et du Brésil (1826), de Januário da Cunha Barbosa, Parnaso Brasileiro (1829-31) e de João de Almeida Garrett, Bosquejo da história da poesia e língua portuguesa (1826).

${ }^{3}$ Recordamos aqui que a noção de "monumento", como é utilizada durante quase todo o século XIX, reporta-se também a grandes coleções de documentos, quando, conforme observa Jacques Le Goff, monumento e documento se aplicam de forma intercambiável até o fim do século, quando a noção de "documento" se impôs no fazer historiográfico com sua acepção de "prova" ou "evidência". Característica em ambos os termos é sua utilização pelo poder, enquanto produtos das sociedades históricas que os fabricaram, segundo determinadas relações de força, consistindo de "um esforço para impor ao futuro - voluntária ou involuntariamente -determinada imagem de si próprias". Ver LE GOFF, Jacques. "Monumento/documento". In: História e Memória. São Paulo: Unesp, 1992.p. 536 e p.548. 
Uma vez que a cultura escrita fosse eleita como um dos elementos civilizatórios mais relevantes, a condição de civilização acompanhava a instituição de uma tradição intelectual que se cristalizou na memória coletiva da comunidade nacional como sua herançae patrimômino. Como constatou Maurice Halbwachs, lembranças individuais, tais como as ideias e símbolos, produzidas socialmente e compartilhadas pelo grupo social, são responsáveis por consolidar o vínculo com a comunidade afetiva. (HALBWACHS, 1990, p.54).

Pode-se aferir, então, que os grandes escritores e suas obras se tornaram referências para esta comunidade afetiva, no momento em que a literaturabrasileira era considerada por muitos como umapêndice obscuro da portuguesa, outro aspecto de disputa com relação aos lusitanos. Custou extensos debates e polêmicas nas revistas literárias e muitos bosquejos de história da literatura para afirmá-la como autônoma.

Desta forma, a tarefa do literato era também a do historiador: arrolar entre seus antepassados grandes homens, criando uma identificação entre o passado e o presente, projetando-os em direção a um futuro promissor, favorecendo ao Brasil um lugar entre as nações. A temática do gênio nacional, ou do grande homem, como é chamado, cruzava-se com a da afirmação da nação e da literatura nacional. O ensaio de Gonçalves de Magalhães, de 1836, ecoa uma afirmação de Madame de Staël sobre o gênio, ou o grande homem:

Nós pertencemos ao futuro, como o passado nos pertence. A glória de uma nação, que existe, ou que já existira não é senão um reflexo da glória de seus grandes homens; de toda a antiga grandeza da pátria dos Cíceros, e dos Virgílios apenas restam suas imortais obras(...) O aparecimento de um grande homem é uma época para a história, e semelhante a uma jóia preciosa, que só possuímos quando a podemos possuir (...)Ele existe no meio de nós sem ser conhecido, sem se conhecer a si mesmo, como o ouro 
nas entranhas da terra, e só espera que desencavem para adquirir seu valor. (MAGALHÃES,1836, p.138)

Como uma "jóia preciosa", como o "ouro" desencavado das "entranhas da terra", o grande homem é a maior riqueza do país. Além de raros, permaneceriam desconhecidos, eles próprios sem tomar consciência de seu valor social, não fosse pelo duro trabalho de detecção e lapidação empreendido pelos modernos literatos.

\section{A estética romântica e a questão do gênio}

Em Paris, Gonçalves de Magalhães assistiu às concorridas aulas de Victor Cousin e provavelmente referenciou-se em Madame de Stäel - intérprete e vulgarizadora dos alemães, os irmãos Friedrich e August W. Schlegel - para escrever seu ensaio sobre literatura no qual aludia à proeminência do gênio criador. A ideologia do gênio criador e desinteressado, garantia a originalidade da obra e elevava a imaginação, à qualidade de faculdade fundamentale autônoma no processo de criação ea tornou característica da estética do Romantismo. ${ }^{4}$ Estava relacionada a novas acepções de arte e de estética, segundo as quais o autor deveria evitar seguir modelos, imitar predecessores ou obedecer a regras da composição, como, por exemplo, a separação rígida entre os gêneros literários e a autoridade dos clássicos. O gênio é criador, poeta e profeta, designado a cumprir "uma missão puramente espiritual, para uns, missão social, para outros, a nítida representação de um destino superior, regido por uma vocação superior.É o bardo, o profeta, o guia"(CANDIDO, s/d, p.25). Junto com a valorização do poeta ou literato, começa a ocorrer ao longo da época moderna, a resignificação da própria ação de escrever, ou do substantivo "escritor" enquanto autoridade máxima de sua obra.(CHARTIER, 1999).

\footnotetext{
${ }^{4}$ Para esta discussão aprofundada ver ANDRADE, Débora El-Jaick. Aárvore e ofruto: $a$ promoçãodos intelectuais no século XIX. Niterói: UFF, 2008. (Tese de Doutorado)
} 
$\mathrm{Na}$ época do Romantismo, junto à língua nacional, a literatura foi considerada marca de identidade histórica de um povo, desde que J. G. Herder reabilitou a poesia popular, presente em autores como Homero e Shakeaspere, e a transformou em manifestação superior do gênio. Enquanto modelo a ser seguido, a biografia do poeta se revestia de particular interesse no Romantismo, posto que a obra é entendida como expressão da personalidade do gênio. Assim, saber como e em que contexto o escritor viveu, recuperar vestígios e informações biográficas, tudo isto consistia uma importante ação pedagógica.

O conjunto de referências literárias dos escritores modernos perfazia uma tradição ou um panteão, em que figuravam Dante, Shakespeare, Ariosto, Tasso, Cervantes, Caldéron, Lope de la Vega e Goethe, que passaram a fazer parte do cânone romântico (NUNES, 2002,64), ou seja, do conjunto de referências dentre os "escritores modernos" que atestariam a precedência da literatura cristã sobre a clássica.

\section{O Camões de Almeida Garrett: o destino maldito do gênio}

Dentreosescritores quese notabilizaramporseu gênio, sobressaiuse o nome de Luís Vazde Camões, cuja imagem abstrata, que personificou o poeta, tomou precedência sobre o indivíduo real. A revalorização, de forma pioneira no século XIX pelos alemães, ocorre em um momento de consolidação nacional, quando a cultura é ela mesma nacionalizada como expressão de um dado povo, língua e de um Estado territorialmente delimitado, quandoopoetatorna-seexemplardeumaconsciênciaeuropéia (COCHRAN, 2001, p.121). O poeta se tornou representante de uma ideia, da época de ouro de Portugal e do ápice do florescimento da literatura portuguesa do classicismo.

De fato, apesar do valor promocional do épico sobre as viagens de Vasco da Gama e dos heróis portugueses que contornaram o Cabo 
da Boa Esperança, e abriram nova rota para a India, a narrativa povoada de divindades pagãs teve pouca projeção na época, inclusive entre a aristocracia. Diversamente, o poema seria apropriado como símbolo da libertação nacional do domínio espanhol no século XVII. Símbolo de nacionalidade, Camões tornou Portugal protagonista de seu poema épico Os Lusíadas, uma epopéia sobre as conquistas marítimas e a luta contra os mouros. Desde o século XVII, Camões era denominado "príncipe dos poetas portugueses" e Os Lusíadas foi traduzido nas línguas inglesa, castelana, italiana, francesa e alemã e já era familiar a muitos escritores modernos, dentre eles, Cervantes, Voltaire e Goethe.

$\mathrm{O}$ culto à Camões, iniciado ainda no século XVI, acaba, assim, transcendendo as próprias fronteiras nacionais; ele passa a ser apreendido como poeta universal. Foi tardiamente revelado nos círculos cultos alemães, por August W. Schlegel em suas lições sobre literatura e arte, Vorlesungen über schöne Literatur und Kunst ocorridas em Berlim de 1801 a 1804 e incluídas em sua antologia sobre literatura latina Blumensträusse italienischer, spanischer und portugiesischer Poesie (1804) e, principalmente por Friedrich Schlegel, em seu curso sobre literatura, ministrado entre 1803 e 1804 em Paris e publicado na obra Geschichte der europäischen Literatur (1803). Nela F. Schlegel comparava Camões a Homero e Virgílio, concluindo que o primeiro conseguira compor o poema heróico nacional onde os antigos fracassaram; aludia o fato de ter sido soldado e cavaleiro e de ter vivido na India, pois por conta disto, seu poema "transpira coragem heróica", impregnado de intuição e experiência. Professa Schlegel: "Uma tal tapeçaria de infinita vida, apresentada de maneira tão rica, tão reluzente, tão própria e tão madura, e com uma tal leveza e claridade, só se encontra nos cantos homéricos". (SUZUKI, 2000).

Dessa maneira, no século XIX, não apenas a obra Os Lusíadas se torna objeto de interesse, mas a biografia de Camões mereceu especial atenção da comunidade letrada. Conforme observou Eduardo 
Lourenço, é durante o Romantismo que nomes como o de Camões, Tasso, Cervantes e Shakespeare deixam de ser apenas grandes homens dignos de memória e passam a ocupar o lugar vago no imaginário, devido à ausência de Deus, que até então fôra referência obrigatória na visão de mundo ocidental, efeito do mecanicismo e ateísmo da época das Luzes. (LOURENÇO, 1999, p.55). Precursores do "mal du siècle" e de uma profunda angústia existencial, cada um destes autores seria detentor de um destino maldito, em razão do gênio, se adaptando perfeitamente às exigências da modernidade literária.

Conterrâneo do poeta renascentista, o escritor português Almeida Garrett elegeu Luís de Camões o protótipo do gênio romântico, relendo sua biografia à luz de um período conturbado da história portuguesa - a ocupação militar de 1807, o estabelecimento do rei no Rio de Janeiro e a Revolução liberal do Porto, da qual Garrett tomou parte. O autor inovou o panorama literário quando em 1825, exilado em Havre, na França, publicou um longo poema, Camões, em homenagem ao maior poetaépico de seu país.

À esta altura, Luís de Camões já era bem conhecido na França. Conforme indica no prefácio do poema: "Tam sabido é a fábula ou enredo dos Lusíadas, e a vida de seu auctor, que nem tenho mais explicações a fazer a este respeito...". (GARRETT, 1825, p.vi). Madame de Stäel, por exemplo, possivelmente foiapresentada ao poeta luso por August Schlegel e não apenas se interessou em traduzir o épico camoniano, mas publicou um verbete biográfico sobre o autorna Biographie Universelle de Michaud em 1812, no qualenfatiza inveja dos contemporâneos do lusitano, seguidores dos clássicos, enquanto Camões seria inspirado pela história e costumes de seu país e século, e pela literatura cristã e cavaleresca, tal qual Dante, Petrarca e Ariosto haviam sido e, portanto, amargou o desconhecimento, a miséria e o esquecimento. (STAËL,1812, p.618-621)

Alguns anos antes de Garrett escrever seu poema, o tema da morte de Camões apareceu em um premiado quadro de Domingos Antonio 
Sequeira (1768-1837), pintor português exilado durante a Reação em Portugal e também em uma composição musical do pianista Domingos Bomtempo (1775-1842) que publicou anos antes, em 1819, sua obraprima, o Requiem (À Memória de Camões) na capital francesa. ${ }^{5}$ No momento em que Garrett dedicava-se à publicação de seu poema, também saía pela Louis Janet Librairie, Scènes de la nature sous les tropiques et leurs influences sur la poesie (1824), deFerdinand Denis, que incluía uma biografia romanceada do grande poeta português, cujo enredo se assemelhava ao de Garrett. (GARRETT, 1825, p.vii.).

O "guerreiro cantor" de Garrett inspirou os literatos portugueses radicados naFrança. (SARAIVA, LOPES, 2008, p. 174). Otópico do exílio é marcante no poema de Almeida Garrett, ele próprio desterrado, em meio à Reação absolutista em Portugal: o golpe miguelista da Vilafrancada que perseguiu principalmente os liberais. ${ }^{6} \mathrm{O}$ Camões de Garrett não deixava de ser panfletário da experiência de uma geração de jovens letrados, frente às intempéries políticas causadas pela mudança de regime. Não obstante, faz parte, sobretudo, da promoção do próprio Garrett, então jornalista e poeta desconhecido, que sobrevivia de traduções e encomendas, um "proscrito", em suas próprias palavras, no momento em que escreveu o poema.(GARRETT, 1839, p.3).

Segundo a representação traçada a partir do poema, a trajetória de Luís de Camões foi marcada pela morte e pela pobreza, desde que combateu nas guerras pelo Império Português, de quando partiu para o Oriente com o escravo Jaú. O "nobre melancólico soldado" experimenta

\footnotetext{
${ }_{5}^{5}$ No ano de 1817, D. José Maria de Sousa Botelho Mourão, Morgado de Matheus, encomendou uma moderna e luxuosa reedição dos Lusíadas à prestigiosa tipografia Didot de Paris e ofereceu-lhe à bibliotecas e institutos. Dois anos depois, em 1819 uma nova edição pela tipografia parisiense foi lançada.

${ }^{6}$ Almeida Garrett participou do período do liberalismo, interrompido pela ascensão da facção conservadora que apoiava o Infante D. Miguel. Foi obrigado a se exilar entre 1823-26, após a Vilafrancada e, denovo, entre 1828-31, na sequência da abdicaçãodeD. Pedro ao trono brasileiro. No regresso a Portugal em 1832, lutou como soldado ao lado de D. Pedro contra os miguelistas, integrando o Batalhão Acadêmico.
} 
uma incrível aventura no mar e se torna poeta. (GARRETT, 1839, p.12). Protegido pelo rei Dom Sebastião, ${ }^{7}$ pelo favor de Dom Aleixo, que teria reconhecido o valor político de sua epopéia glorificante, foi hostilizado por invejosos cortesãos e após a morte do protetor real, amarga a pobreza, desamparado pelos amigos, sustentado apenas pelas esmolas que seu escravo pedia em seu nome. (GARRETT, s/d, p.115; LAJOLO, ZILBERMAN, 2001, p.72). No canto décimo ele escrevia:

Vêde-o, vai pelas sombras caridosas

Da noite, de vergonhas coitadora,

De porta em porta tímido esmolando

Os chorados ceitis com que o mesquinho,

Escasso pão comprar.Daí, portugueses,

Dai esmola a Camões. Eternas fiquem

Estas do estranho bardo memorandas,

Injuriosas palavras, para sempre

Em castigo e escarmento conservadas

Nos fastos das vergonhas portuguesas. (GARRETT, s/d, p.121)

Estes aspectos contribuíram para traçar o perfil de poeta marginal. Sobretudo, o fato de que seu túmulo permaneceu desconhecido dos contemporâneos de Almeida Garrett ${ }^{8}$ é interpretado como ingratidão e evidencia o embate entre criação artística e a luta pela sobrevivência, acabando por reforçar o mito da incompatibilidade entre letras e

\footnotetext{
${ }^{7}$ Os laços de patronagem entre D. Sebastião e Luís de Camões se restringiam a uma pensão de 15 mil réis que recebeu irregularmente por três anos, em retribuição à dedicatória do autor do livro, valor pequeno em relação a outros letrados a seu serviço. Por outro lado, especialistas enfatizam a rapidez com que a obra foi impressa e aprovada pelo censor, indicando que o poeta possuía como protetores personagens influentes, como D. Manuel Conde de Vimioso que mandou imprimir o épico, e D. Luís de Ataúde que intercedeu junto ao rei pela tença. Ver Vitor Aguiar e Silva ed, Dicionário de Luís de Camões. São Paulo:Leia Brasil, 2011.pp.91-92.

${ }^{8}$ Atualmente, sabe-se que um amigo lhe pagou o enterro em 1580, na Igreja de Sant'Ana, perto de um hospital. Ver Maria Vitalina Leal de Matos “Biografia de Luís de Camões”, in Vitor Aguiar e Silva ed, Dicionário de Luís de Camões. São Paulo:Leia Brasil, 2011.pp.80-94 .
} 
dinheiro. ${ }^{9} \mathrm{~A}$ ideia representada pelo poeta renascentista é do sacrifício pela literatura, porque seu valoré perene em contrastecomo mundo materialqueé efêmero.(LAJOLO,ZILBERMAN, 2001,p.73). Contraponto das veleidades do universo cortesão, a missão do poeta, sem título nobiliárquico, alcança um plano quase divino.

Considerando que as fronteiras nacionais não são impermeáveis a trocas culturais, circulação de ideias, modelos e práticas, é possível constatar que os intelectuais, tanto quanto os impressos, atravessavam continentes. As imagens, saberes, motivos artísticos, moldam, se aclimatizam, são apropriadas e reinterpretadas para refletirem problemas e preocupações locais. Carlo Ginzburg observa que "O fato de que certas ideias estejam no arsignifica afinalque,partindodas mesmas premissas, épossívelchegar de maneira indepente a conclusões similares". (GINZBURG, 2007, p.270). Assim, se Os Lusíadas de Camões era facilmente encontrado nas livrarias da sede do Reino Unido (de Portugal Brasile Algarves) - uma nova edição saía imprensa no Rio de Janeiro, pela P. C. Dalbin e Ca em 1821. ${ }^{10}$ Entre 1825 e 1839, o Camões de Garrett passou a fazer parte do imaginário dos homens de letras, que o leram através das edições portuguesas e apócrifas vendidas no Brasil", consolidando lá o "mito de Camões" nas letras, quando o campo literário estava nos primórdios de sua constituição.

A representação do escritor identificado à figura de Camões, através da sua associação à pobreza, ao infortúnio, ao heroísmo e à virtude, vigorou como símbolo também no Brasil, a despeito do forte sentimento antilusitano. A geração de literatos de 1830 e 1840, que

\footnotetext{
${ }^{9}$ Este foi tema do capítulo "Cartas e contas" in O preço da leitura de Lajolo e Zilberman, que relaciona outros escritores que representaram, na ficção, o mito de Camões, tais como Pereira da Silva, Alvares de Azevedo, Castro Alves e Fagundes Varela.

${ }^{10}$ Assim indicam os anúncios de compra e vendana Gazeta do Rio de Janeiro (1812), no Diário do Rio de Janeiro (1824-1840), no Diário Mercantil(1825-26) e no Jornal do Commercio (1828-29).

${ }^{11}$ No prefácio à segunda edição de Camões de 1839 , Garrett diz que em dois anos a $1^{\text {a }}$ edição se esgotou apenas devido à propaganda boca a boca, e apenas é publicizada a venda em Portugal a partir de 1826. Mas uma das razões pelas quais finalmente prepara a $2^{\text {a }}$ edição, são as contrafeições brasileiras da $1^{\mathrm{a}}$ edição. GARRETT, A.Camões. $5^{\mathrm{a}}$ Ed, Lisboa, Casa da viúva Bertrand e Filhos, 1858.p.X.
} 
laboraram em benefício das letras e das artes nacionais, incorporaram o "mito de Camões" para valorizar, a partir do tópos do gênio nacional, os escritores brasileiros.

\section{Camões, Tasso, Antônio José da Silva e a plêiade romântica na literatura brasileira}

Segundo Magalhães (1836, p.143) os poetas, artistas e literatos eram "em vida sepultados" nos conventos e seu talento desperdiçado, situação que, segundo ele analisa, se perpetuaria até o presente, não pela ausência de gênios, mas pela depreciação à qual estão sujeitos:

Se refletirmos, veremos que não são poucos os escritores para um país que foi colônia portuguesa, para um país no qual ainda hoje o trabalho dos literatos, longe de assegurar lhes, com a glória, uma independência individual, e um título demais, ao contrário parece desmerecê-los, e desviá-los da liga dos homens positivos, que desdenhosos dizem: é um Poeta; sem distinguir-se apenas é um trovista, ou um homem de gênio; como se dissessem: Eis ai um ocioso, um parasita, que não pertence a este mundo; deixai-o na sua mania .... (MAGALHÃES, 1836, p.143)

Em Suspiros Poéticos e Saudades, livro de poesias lançado em 1836, mesmo ano que arevista Niterói, Gonçalves de Magalhães, reputado como o iniciador da poesia nacional, menciona Camões, no poema "Sepultura de Filinto Elísio". Diante da sepultura de Filinto Elísio, poeta português, no cemitério Père Lachaise, em Paris, lamentava o destino convergente com o de Camões, sem sepultura, sem fortuna, à mercê do esquecimento ${ }^{12}$ :

\footnotetext{
${ }^{12}$ Filinto Elísio (1734-1819), pseudônimo de Francisco Manuel do Nascimento, foi um sacerdote, poeta e tradutor português, modelo literário de Almeida Garrett, que, acusado pelainquisição por suasidéias liberais, fugiu para Parisonde publicou algumas
} 
Onde é que a ingratidão da injusta Pátria,

Dessa Pátria que honraste

Co'os teus divinos carmes,

Cavou-se a humilde sepultura?-Onde?

D'ela ausente, proscrito, na miséria,

Como Camões viveste;

Saudoso, e só por ela suspirando,

Monumentos ergueste à glória sua;

E surda sempre foi aos teus gemidos;

Como Camões morreste na indigência![...] (MAGALHÃES, 1999,.p.171)

Neste poema há a ideia de que as homenagens e glória póstumas não são capazes de apagar a ingratidão dos contemporâneos que o poeta recebeu em vida, sobretudo a ausência de proteção e remuneração financeira. No verso final, pedia ao Brasil que não seguisse Portugal no desprezo a seus poetas: "Ó Pátria minha, é meu Brasil, não sejas/Como Lísia cruel para teus filhos". (MAGALHÃES, 1999, p.171-172). Salientava, no fim do poema, o valor exemplar de Filinto Elísio para futuros escritores. (MAGALHÃES,1999, p.178).

Anos mais tarde, o pintor Manuel de Araújo Porto Alegre, amigo de Magalhães, atuando como cônsul em Lisboa, visitou o suposto túmulo do poeta renascentista, comentando que: "Parece que a providência quis que aquele que deveria baixar na obscuridade levantasse a maior luz para o seu país e seu próprio monumento e o espalhasse no mundo" (PORTO ALEGRE, 1859, p.46). Na obra Brasilianas (1859), que ofereceu a Pedro II, publicou um poema intitulado "A sepultura de Camões", que escreveu diante do túmulo do poeta português: "A pedra, que a mente de um Phidias transforma/Na imagem do gênio, se o tempo a esborcina,/ É muda, sem alma, sem moto, sem norma;Cadaver de pedra; o que éque ella ensina?". ${ }^{13}$ (PORTO ALEGRE, 1863, p.347).

de suas poesias. Morto no exílio, seus restos mortais foram transladados para Lisboa em 1843. Suas poesias só foram publicadas em Portugal entre 1836-1840.

${ }^{13}$ Mantivemos a ortografia de época, tal qual se encontra na documentação consultada. 
Em outro verso de Brasilianas, Camões é equiparado a César, imperador romano: "Camões era um César: o seu cenotáfio/Avulta na lira, de idade em idade/A pedra que exara mesquinho epitáfio,/Mostrar jamais pode tão grande entidade/.”. (PORTO ALEGRE, 1863, p.347). A origem fidalga não era o motivo de sua grandeza, suas ações e seu talento destacavam-se: as conquistas militares de César e a dedicação camoniana à poesia se perpetuaram na memória das pessoas através dos séculos. Em morte teriam sido mais admirados do queem vida: "Se a inveja dos homens na vida o nodôa/A morte restaura com dupla memória/". (PORTO ALEGRE, 1863, p.347). Esta seria a revanche de Camões: depois de ter sido desprezado, foi reverenciado pela humanidade em um monumento em mármore. Seu túmulo aparece no poema de Porto Alegre como "a pedra da ingratidão".

Em outro verso, Porto Alegre menciona dois reis: Camões e o jovem rei de Portugal D. Sebastião (1544-1578), a quem foi dedicado $O$ s Lusíadas em 1572:

Viu dois reis abandonados

Perecerem desgraçados:

O das armas, pela insânia.

Sobre o chão da Mauritânia,

Sem um sepulcro real!

$\mathrm{O}$ da lira sem igual,

Sobre a enxerga em que expirou,

Como um vil que se atirou

As portas de um hospital?

Foi terrível punição

Após tanta heroicidade:

Foi a voz da divindade

Quem te deu a maldição!

De teus reis a ingratidão

Foi tamanha em plenitude,

Que o Galvão deu servitude, A Albuquerquea iniqüidade, 


\section{A Pacheco a crueldade,}

E a Camões desprezo rude. ${ }^{14}$ (PORTO ALEGRE, 1863, p.351-52)

D. Sebastião, o desejado, pretendia restaurar o império de seus antecessores e era a última esperança da linha sucessória portuguesa, após a morte de seu avô, D. João III. A morte na batalha de Alcácer Quibir em 1578, em meio à luta pela reconquista das possessões territoriais lusitanas aos mouros no norte da África, colocou fim à independência do país e à dinastia de $\mathrm{Avis}^{15}$, recaindo o reino sob o domínio espanhol. $\mathrm{O}$ desaparecimento de seu corpo e a dúvida a respeito de seu sepultamento inauguraram um mito milenarista secular que ultrapassou as fronteiras nacionais e supunha o retorno do monarca desaparecido: o sebastianismo. A tradição oral transformou D. Sebastião em mito, tal qual Camões que, produto do humanismo português, representou todo um século de ouro da literatura e cultura, animado pelo mecenato dos reis D. Manoel e D. João III, que promoveram a valorização das letras nos círculos cortesãos, ainda pouco versados. Teria seguido ao seu desaparecimeto, a decadência das letras e da política, com as perdas coloniais na África e o acirramento da censura inquisitorial.

No poema de Porto Alegre, tanto a lírica de Camões quanto a luta de D. Sebastião, recordavam de modos diversos um tempo de glória da pátria lusa, o período manuelino durante a primeira metade do século XVI, quando os descobrimentos dinamizaram o comércio marítimo português e a economia do reino, trazendo prosperidade à Corte è nobreza. Porto Alegre compara Camões a outros navegadores que eram igualmente cronistas, dotados da cultura humanista, que serviram ao rei nas armas e nas letras, e, tendo sido heróis em seu tempo, acabaram esquecidos pela posteridade.

\footnotetext{
${ }^{14}$ Refere-se às figuras renascentistas de Antônio Galvão, cronista e administrador colonial, autor de Tratado dos Descobrimentos (1563), Afonso de Albuquerque, fidalgo, militar e vice-rei da India, e Duarte Pacheco Pereira, navegador e autor de Esmeraldo de situ Orbis

${ }^{15} \mathrm{Na}$ história política de Portugal, a dinastia de Avis foi sucedida pela dinastia espanhola de Habsburgo, que ascendeu ao trono português em 1580, após a morte do tio avô de D.Sebastião, cardeal D. Henrique.
} 
Os dois corpos desaparecidos, do rei e do escritor, dois mitos cuja força atravessou séculos, são assemelhados na heroicidade, no martírio e na capacidade de regeneração. Ele se refere a Camões como "mártir da inteligência", após o desaparecimento de seu protetor e observa: "Vejo glória na indigência". (PORTO ALEGRE, 1863, p.349). Acrescenta: "Era um rei para o futuro /O mendigo do presente/". (PORTO ALEGRE, 1863, p.351). Nesta passagem ele certamente valoriza a indigência e a miséria, coerentes com o destino do gênio, figura marginalizada em seu tempo; Camões é um espelho para os poetas do presente.

Em Suspiros Poéticos e Saudades (1836) Magalhães arrolava as grandes referências literárias do Romantismo, Homero, Camões e Dante, todos detentores de destinos trágicos:

Aquele a quem a Grécia ergueu altares,

Homero, mendigou de porta em porta!

$\mathrm{Tu}$, ó Ravena, o fugitivo Dante

Viste iracundo praquejar seu fado!

Camões, rival de Tasso, o pão esmola

Ante os olhos de Lísias. E tu, ó Silva,

Da minha Pátria filho,

A fogueira subsiste com pé firme,

Que a inocência teus passos vigorava;

E entre as chamas, por mãos ímpias acesas

Teu último suspiro ao céu ergueste. (MAGALHÃES, 1999, p.256-259)

Magalhães alude aos sofrimentos dos escritores, mártirese vítimas da ingratidão do mundo que, como Tasso, "mais sofreram na vida que com a morte", pois ela lhes garantiria novo e imortal viver na memória coletiva. Homero que como Camões mendigou de porta em porta, o fugitivo Dante e o perseguido Silva - Antonio José da Silva, dramaturgo queimado como herege pela inquisição - seriam consagrados enfim pela história da literatura, à medida que ela fosse escrita. 
Para demonstrar este tópos, escolheu Antônio José da Silva como protagonista de sua tragédia O poeta e a inquisção (1837). Antônio José, era nascido no Rio de Janeiro em 1705, no seio de uma abastada família de cristãos-novos. Instruiu-se em Lisboa e depois em Coimbra, para onde acompanhou a mãe aos seis anos, acusada de judaísmo. Alguns anos depois, quando já redigia, dirigia e produzia suas peças populares de teatro de bonecos, chamadas "óperas", no Teatro do Bairro Alto, em Lisboa, foi denunciado por uma escrava como judaizante, processadoe torturado duas vezes pela inquisição, e em 1739 subiu ao patíbulo para ser queimado vivo.

Embora tenha composto suas peças em Portugal, Magalhães o considerou um literato brasileiro, em "Breve notícia sobre Antonio Joséda Silva" de seu $O$ poeta e a inquisição seria a "primeira tragédia escrita por um Brasileiro, e única de assunto nacional". (MAGALHÃES, 1865). A tragédia, baseada em fatos reais e fictícios, foi encenada no teatro Constitucional Fluminense, no Rócio, no centro do Rio de Janeiro, em 1838, protagonizada pelo já célebre ator João Caetano dos Santos que renovou as técnicas de arte dramática então em voga no Brasil. No texto ficcional, Antonio José, protegido pelo Conde deEriceira, literatoligadoà alta nobreza portuguesa, é perseguido pelo vilão, o inquisidor dominicado frei Gil, abrigado pela atriz e amiga Mariana. Descoberto e encarcerado, sacrifica-se por sua arte para a posteridade, que constitui a lição moral da peça. Esta moral pode ser apreendida em diversos diálogos, como o que se deu no primeiro ato, cena três, entre a criada Lúcia e a comediante Mariana, amiga do poeta:

LÚCIA- Oh! certamente que me causa pena.

Tanto eu não poderia: antes quisera

Uma esmola pedir de porta em porta,

Do que seguir tal gênero de vida.

Eentão porque ralar sua existência?!

Para agradar ao povo! e apresentar-se 
A rir, ou a chorar, como uma doida!

MARIANA - Que dizes tu? Coitada! o teu discurso

Bem mostra que da glória o amor não sentes.

LÚCIA - Não sinto, e queira o céu que eu nunca o sinta;

$[\ldots]$

Só quero amar a Deus... Diga, senhora,

Porventura Camões amava a glória ?

MARIANA - Oh, se a amava!... E que luso depois dele tanto amou-a?

LÚCIA - Pois bem, sempre foi pobre;

Na miséria viveu, pedindo esmolas,

E morreu no hospital. Senhor Antônio

Que lhe diga o que ganha com as comédias

Que ele compõe, para agradar ao povo.

MARIANA - Ganha a reputação de Plauto Luso, de um ilustre

escritor, de um grande homem.

LÚCIA (Com ar de compaixão) - Melhor fora dizer - de um pobre homem.

MARIANA - E o que tem a pobreza com o talento?

LÚCIA - Muito; que em Portugal andam casados.

E se o senhor Antônio continua,

Já lhe prevejo um fim bem miserando.

Eu só ouço dizer que ele é jocoso,

Que faz as pedras rir: eis porque o amam.

E se não fosse a banca, e os demandistas

Que lhe dão de comer, creiodecerto

Que ele morto estaria há muito tempo,

Ou pelas portas pediria esmola

Como o pobre Camões... Camões!... Coitado!

(MAGALHÃES,1865,pp.15-17) 
Na cena, a criada alude à sorte de Antônio José associada à triste trajetória de Camões, que reunia "a pobreza com o talento". Em seguida, Lúcia deseja que seu filho, que erra pelo mundo, nunca se tornasse um poeta, para que pudesse conhecer a felicidade.

Assim como Araújo Porto Alegre comparou a condição do homem de gênio à do escravo, Gonçalves de Magalhães a compara à do indigente e a do serviçal. É a criada Lúcia, que contrasta com o protagonista por ocupar posição inferiorna hierarquia social, quemevidencia, na percepção do autor, uma inversão de valores. Ao sentir pena da comediante Mariana e do poeta Antônio José, provoca a associação de todos os artistas e poetas ao incomparável escritor luso, lembrado pela sua celebridade, mas também pela pobreza em que passou seus últimos dias. Lúcia personifica a sociedade, que abomina a sorte do poeta por não compreender sua missão, e tenta dissuadir Mariana de seguir o mesmo fim. A resposta de Mariana parece confirmar as intempéries e o destino inequívoco do gênio: a pobreza, o desprezo e a morte.

\section{Considerações finais}

Concluí-se que se o século XIX acenou com novas possibilidades aos escritores públicos, capazes de intervir na opinião pública através da imprensa e não alterou essencialmente a condição de dependência, quer seja dos empregos públicos, quer seja do mecenato, ainda que o mercado editorial ganhasse cada vez mais espaço. Confrontados com o dilema de quem vivia da pena, divididos entre o dinheiro e a liberdade de criação literária, paradoxalmente os literatos revestiam de distinção o oficio do escritor através das referências a poetas do passado. 


\section{Referências}

ANDRADE, Débora El-Jaick. A árvore e ofruto: a promoção dos intelectuais no século XIX. Niterói: UFF, 2008.(Tese de Doutorado)

CANDIDO, Antonio. A Formação da Literatura Brasileira. 9a ed., Belo Horizonte: Itatiaia Ltda. Vol 1 e 2. v.1. 1750-1836 -- v.2.

CANO,Jefferson. APolítica daLusofobia:Partidose IdentidadesPolíticas no Rio de Janeiro (1848-1849). In:Locus.revista de história.Juizde Fora,v.13, n. 1.p. 63-92, 2007.

CHARTIER, R. A ordem dos livros. Brasília: UnB, 1999.

COCHRAN, Terry. The epic figure of literary history.Twighlight of the literary: figures of thought in the age of print. Cambridge: Harvard College, 2001.

FONTANA, Josep. História:análise do passado e projeto social. Bauru/São Paulo: Edusc, 1998.

GARRETT, Almeida João B."Prefácio da $2^{\mathrm{a}}$ edição". In: Obras de J.B. de Almeida Garrett; Camões. Lisboa: Typographia de José Baptista Morando, 1839.

“Prefácio". In: Camões, poemas. Paris: Livraria Nacional e estrangeira, 1825.

. Camões. $5^{\mathrm{a}}$ Ed, Lisboa, Casa da viúva Bertrand e Filhos, 1858.

. Camões. s/l, Ed Porto,s/d.Biblioteca Digital.

GINZBURG, Carlo. O Fio e os Rastros: verdadeiro, falso, fictício. São Paulo: Companhia das Letras, 2007. 
HALBAWCHS, Maurice. A Memória Coletiva. SP:Edições Vértice, 1990.

HERDER, J. G. Shakespeare. New Jersey: Princeton University Press, 2008.

LAJOLO, Marisa \& ZILBERMAN, Regina. O preço da leitura.São Paulo: Ática, 2001.

LE GOFF, Jacques. Monumento/documento. In: História e Memória. São Paulo, Unesp, 1992.

LOURENÇO, Eduardo. Mitologia da saudade, seguido por Portugal como destino. SP: Companhia das Letras, 1999.

MAGALHÃES, D.JG. Suspiros Poéticose Saudades. Brasília:EdUnB, 1999.

.Tragédias, Antonio José, Olgiato, Othelo. Rio de Janeiro: Livraria B.

$\mathrm{L}$ de Ganier, 1865.

.Ensaio sobre a história da literatura brasileira. In: Revista Niterói. Paris, Libraire Dauvin et Fontaine, ${ }^{\circ} 1,1836$.

MIRANDA, Joséda Costa. Camões/Tasso:Um confronto e algumas semelhanças segundo a crítica. Coimbra: Universidade de Lisboa, 1985.

NEVES, Lúcia Bastos. "Estado e política na independência", in Keila Grimberg e Ricardo Salles eds. O Brasil Imperial, (Rio de Janeiro, Civilização Brasileira, 2011)1:97.

NUNES, Benedito.A visão romântica. GUINSBURG, J. O Romantismo. São Paulo: Perspectiva, 2002. 
PORTO ALEGRE, Manoel de Araújo. Brasilianas. Viena: Imperial e Real Tipografia, 1863.

. Diário Pessoal. 7 de junho de 1859.página 46. Centro de Memória da Academia Brasileira de Letras. (Pasta 9-3-2 Doc 394-0-1).

SARAIVA, Antonio, LOPES,Oscar.História da Literatura Portuguesa. Lisboa,Porto editora, 2008.

STAËL, Madame (Anne-Louise Germaine Necker). Biographie Universelle ancien etmoderne. Michaud Frères Librairie, 1812. Tome 6éme.pp.618-621.

SUZUKI, Márcio. Dois trechos de Friedrich Schlegel. Caderno Mais. Folha de São Paulo.SP, 21/05/ 2000. Disponível em <http://www1.folha.uol. com.br/fsp/mais/fs2105200013.htm> 
Revista Leitura V. 2 n$^{\circ} 57$ - jul/dez 2016 - Poesia e História 